\title{
Factors Determining the Choice of Place of Delivery among Antenatal Attendees in Primary Health Care Centres in Lafia Nigeria
}

\author{
Ikrama Hassan ${ }^{1}$, Edna Philip ${ }^{2}$, Anazodo Michael ${ }^{1}$, Ann Joshua ${ }^{3}$, Lawal Abdulmumuni \\ Ahmed $^{4}$, Babatunde Joseph ${ }^{1}$, Bello Surajudeen Oyeleke ${ }^{5 *}$, Sasetu Stephen ${ }^{6}$ \\ ${ }^{1}$ Epidemiology and Community Health Department, Dalhatu Araf Specialist Hospital, \\ Lafia Nasarawa State, Nigeria \\ ${ }^{2}$ Nursing Department, Dalhatu Araf Specialist Hospital, Lafia Nasarawa State, Nigeria. \\ ${ }^{3}$ Planning, Research and Statistics Department, Ministry of Health, Lafia Nasarawa State, \\ Nigeria \\ ${ }^{4}$ Department of Anatomy, Federal University of Lafia, Lafia Nasarawa State, Nigeria \\ ${ }^{5}$ Paediatrics Department, Dalhatu Araf Specialist Hospital, Lafia Nasarawa State, Nigeria \\ ${ }^{6}$ Planning and Statistics Department, Nasarawa Primary Healthcare Development Agency, \\ Lafia Nasarawa State, Nigeria
}

\begin{abstract}
Unskilled home delivery is a threat to maternal and child health. In Northern Nigeria, many pregnant women attend antenatal care but opt to deliver at home. This study determined knowledge on pregnancy outcome, the burden of home delivery, and factors contributing to the choice of place of delivery. A cross-sectional study was done with the subjects selected by multi-stage sampling. The data was analyzed using SPSS. Results were presented in frequencies and percentages with chisquare used in determining the statistical significance between the socio-demographic characteristics and the choice of a planned place of delivery. The mean age of participants is 27.6 \pm 5.0 years. Of the 404 participants and $43.3 \%$ are from the lower social status. Most participants were delivered at home due to sudden labour (25.6\%), lack of transportation (20.5\%), high cost of hospital deliveries (13.7\%). Most understand that leg swelling may connote problems in Pregnancy, Hypertension can occur in Pregnancy, and a normal pregnancy may become complicated. Educational status, health worker's attitudes, previous experience, ease of transportation, and numbers of parity are all significant determinants of the choice of place of delivery ( $p<0.0001)$. Most participants delivered in the hospital, but a significant number still delivers at home despite knowing that Hypertension can occur in Pregnancy and that normal Pregnancy can become complicated. Reasons for their decision were lack of transportation means, an attitude of healthcare workers, and high cost of hospital deliveries. The major determinant of choice of delivery place is; educational status, previous experience, and attitude of healthcare workers.
\end{abstract}

Keywords: Choice, Determining, Delivery, Factors, Place, Pregnant.

\section{Introduction}

A great number of women and their unborn babies lost their lives in sub-Saharan Africa from Pregnancy-related complications [1]. Globally, approximately 830 women die every day from preventable and childbirth [1]. In our resource-poor settings, home delivery is usually the cheapest option but is associated with risks of infection and lack of available equipment in the event of complications [2]. Many women, especially in sub- Saharan countries, were not lucky enough to be cared for 
during Pregnancy and childbirth by qualified healthcare personnel [2]. Skilled care, before, during, and after childbirth, can save the lives of women and newborn babies [3]. The level of assistance that a woman receives during childbirth is a strong determinant of the overall outcome for her and her newborn [4]. The presence of a skilled attendant during birth is therefore imperative. The term 'skilled attendant' refers to caregivers with midwifery skills, such as physicians and other qualified healthcare workers $[4,5]$.

Nigeria has continued to witness a high death of women relating to Pregnancy with substantial variations across its regions [6]. Despite this, the use of reproductive health services remains low, and home delivery among childbearing age is more and widespread. Hence maternal morbidity and mortality remain a public health problem [2]. This may be influenced by a lot of factors, including demographic, socio-economic, cultural, Obstetric, and health system factors [7].

In Nigeria, most deliveries take place at home or with the Traditional Birth Attendants (TBAs). In Nigeria, $25 \%$ and $60 \%$ of pregnant women in rural and urban areas respectively uses delivery services at health care facilities [7]. In Kano, Northern Nigeria, the majority $(74.1 \%)$ of the women between the ages of 25 35 years deliver at home, mainly due to health worker's attitudes and the presence of male healthcare workers during delivery [7].

Nasarawa State, which is located in North Central Nigeria, is reported to have the highest rates of maternal mortality ratio within the region, 700 women per 10,000 live births and 103 children per 1,000 live births annually, with an approximate population of over 200 million citizens [8]. Home delivery in Nasarawa State, Nigeria, is common and is one of the major causes of maternal and infant mortality in the state. In Nasarawa State, $80 \%$ of home deliveries are conducted by unskilled birth attendants (mostly family members) [9].
The poor organization has been a major challenge in Nigeria [10]. [11] asserted that maternity care in Nigeria is organized around three tiers the primary, secondary, and tertiary care levels. Pregnant women are to receive antenatal care, natal and post-delivery care at the primary health centers nearest to them [12]. In Nigeria, the maternal mortality rate is high, with maternal deaths the highest in the world after India [13].

The Nigerian health system as a whole has been plagued by problems of service quality, including unfriendly staff attitudes to patients, inadequate skills, decaying infrastructures, and chronic shortages of essential drugs. Approximately two-thirds (2/3) of all Nigerian women deliver outside the facilities and without a medically skilled attendant present.

\section{Rationale for the Study}

The maternal mortality rate is known to be higher in the Northern region. The exact burden has not been well delineated in Nasarawa State, North-Central Nigeria. Some women attend antenatal care but will end up delivering at home rather than in the hospital.

This motivates the researchers to carry out this study so as to determine the factors influencing the choice of delivery place among antenatal attendees in Lafia Nasarawa State, Nigeria.

\section{Specific Objectives}

1. To ascertain the choice of delivery place among ANC attendees in PHC clinics in the Lafia metropolis.

2. To assess the knowledge of ANC attendees on skilled birth delivery.

3. To determine factors that influence the choice of delivery place among these clients.

\section{Methodology}

The study was conducted in two PHCs situated in Lafia metropolis, the state capital. Hausa is the unofficial lingua franca of the 
people of the area, and the major occupations are farming, trading, and civil servants.

\section{Study Design}

This was a cross-sectional prospective study.

\section{Sample Size Estimation}

The sample size was calculated using the formula:

$$
\begin{aligned}
& n=\frac{Z^{2} p+q}{d^{2}} \\
& =\frac{Z^{2} p(1-p)}{d^{2}}
\end{aligned}
$$

$\mathrm{n}=$ is the initial sample size

$\mathrm{p}=$ Prevalence of pregnant women who prefer home delivery from a previous study $=39.3 \%$ [14].

$\mathrm{q}=1-\mathrm{p}$.

$\mathrm{Z}_{\mathrm{a} / 2}=1.96$ (alpha deviate confidence level)

$\mathrm{P}=39.3 \%[14]$

$\mathrm{q}=1-0.393=0.607$.

$\mathrm{d}=0.05$

$$
n=\frac{1.96 \times 0.393 \times 0.607}{0.05^{2}}
$$

$\mathrm{n}=366.56$.

$\mathrm{N}=$ is the final sample size.

$10 \%$ is added for Non-Response Rate (NRR)

$=10 \%$ of $366.56=36.656$.

$\mathrm{N}=366.56+36.656=404$.

Therefore, the minimum sample size calculated was 404 .

\section{Sampling Technique}

A multi-stage sampling technique was used to select one ward each from Lafia Township and another from the lafia environs using random sampling. One Primary Healthcare Centres (PHC) is then selected from each of the two wards earlier selected also using a simple random sampling method.

The pregnant women attending the selected PHC for Antenatal Clinic (ANC) were then approached; the study explained to them in detail and is recruited through a convenient sampling after obtaining an informed consent until the desired number (202 per PHC) is attained.

\section{Inclusion Criteria}

All pregnant women who have delivered once or more and attends antenatal care in those two PHCs were eligible to be chosen.

\section{Exclusion Criteria}

Pregnant women that are primigravida (first Pregnancy).

\section{Data Collection Procedure}

A questionnaire-based study. The first section seeks for socio-demographic background, while the second section seeks to evaluate the factors affecting the choice of delivery place among antenatal attendees in PHC clinics within the Lafia metropolis. The questions are closed-ended, with few requesting for an explanation on their responses.

\section{Statistical Analysis}

The data analysis was with SPSS version 23.0, and the result was presented in tables while chi-square was used to assess the statistical significance between the sociodemographic characteristics and choice of a planned place of delivery.

\section{Confidentiality of Data}

Data de-identifiers were used, stored in a mini-computer that is pass-worded, and kept in a safe locker where only the principal author had access to it. All data collected was protected against unlawful or unauthorized access, disclosure, or theft. All information was kept secret and confidential to prevent legal or reputational damage and other severe consequences.

\section{Results}

\section{Socio-demographic Characteristics}

There were 404 women of reproductive age in the study, giving a response rate of $100 \%$ with an average of 27.6 years \pm 5.0 years, most 
of which were aged $21-30$ years equivalent to $256(63.5 \%)$. More than two-thirds of the participants $(81.5 \%)$ had secondary or tertiary education, with half $(50.2 \%)$ of them engaged in petty businesses. Most are married (98.7\%) and from monogamous families ((73.9\%). Also, more than a third $(43.3 \%)$ belonged to the lower social class Table 1 .

Table 1. Socio-demographic Characteristics

\begin{tabular}{|c|c|}
\hline Variables & Frequencies n (\%) \\
\hline \multicolumn{2}{|l|}{ Age group } \\
\hline$\leq 20$ & 49 (12.2) \\
\hline $21-30$ & $256(63.5)$ \\
\hline $31-40$ & $96(23.8)$ \\
\hline $41-50$ & $3(0.5)$ \\
\hline \multicolumn{2}{|l|}{ Marital status } \\
\hline Single & $2(0.5)$ \\
\hline Married & $398(98.7)$ \\
\hline Divorced & $4(0.7)$ \\
\hline \multicolumn{2}{|c|}{ Type of marriage } \\
\hline Monogamous & $290(73.9)$ \\
\hline Polygamous & $114(26.1)$ \\
\hline \multicolumn{2}{|l|}{ Religion } \\
\hline Christian & $145(35.7)$ \\
\hline Muslim & $259(64.3)$ \\
\hline \multicolumn{2}{|c|}{ Educational status } \\
\hline None & $19(4.5)$ \\
\hline Primary & $57(14.0)$ \\
\hline Secondary & $173(43.0)$ \\
\hline Tertiary & $155(38.5)$ \\
\hline \multicolumn{2}{|l|}{ Occupation } \\
\hline Housewife & $110(27.2)$ \\
\hline Farming & $24(5.9)$ \\
\hline Artisan & $28(6.9)$ \\
\hline Petty trading & $203(50.2)$ \\
\hline Civil servant & $39(9.8)$ \\
\hline \multicolumn{2}{|l|}{ Social status } \\
\hline Lower class & $175(43.3)$ \\
\hline Middle class & $137(33.9)$ \\
\hline Higher class & $92(22.8)$ \\
\hline
\end{tabular}

Mean age of the ANC attendee $27.60 \pm 4.98$

\section{Factors Determining Choice of Delivery Place}

Most $332(82.2 \%)$ chose to deliver in the hospital. Reasons for some participants (17.8\%) who still chose home delivery for delivery of their index pregnancies included; sudden labour
\& delivery (25.6\%), distance to the health facility and lack of transport means (20.5\%), and high cost of care associated with hospital deliveries $(13.7 \%)$.

Of the respondents, $(29.0 \%)$ confirmed that their last deliveries were at home. Close to a third (31.6\%) of those preferring home delivery 
will be delivered by the TBA. Of those that chose home deliveries with the TBAs, $(70.3 \%)$ are happy with the 'treatment' accorded them by the TBAs. The reasons for preferring TBAs are; Attention given to them (46.2\%) and lower cost $(23.1 \%)$ Table 2.

Table 2. Factors Determining Choice of Delivery Place

\begin{tabular}{|c|c|}
\hline \multicolumn{2}{|l|}{ Choice of place of delivery Frequencies n (\%) } \\
\hline \multicolumn{2}{|l|}{ Where do you choose to deliver your current Pregnancy } \\
\hline Home & $72(17.8)$ \\
\hline Hospital & $332(82.2)$ \\
\hline \multicolumn{2}{|l|}{ Place of the previous delivery } \\
\hline Hospital & $287(71.0)$ \\
\hline Home & $117(29.0)$ \\
\hline \multicolumn{2}{|l|}{ Reasons for delivering at home } \\
\hline Distance/lack of transportation means to the Hospital & $24(20.5)$ \\
\hline High cost of hospital delivery & $16(13.7)$ \\
\hline Attitude of HCW & $5(4.3)$ \\
\hline Sudden labour / delivery & $30(25.6)$ \\
\hline No reason & $5(4.3)$ \\
\hline My neighbour is a Nurse/Midwife & $6(5.1)$ \\
\hline No available bed space in Hospital & $4(3.4)$ \\
\hline My husband insisted I deliver at home & $8(6.8)$ \\
\hline Convenience & $7(6.0)$ \\
\hline Personal choice to deliver at home & $7(6.0)$ \\
\hline No sign of complication & $5(4.3)$ \\
\hline \multicolumn{2}{|l|}{ Who conducted the home delivery } \\
\hline Midwife & $32(27.4)$ \\
\hline CHEW & $34(29.0)$ \\
\hline TBA & $37(31.6)$ \\
\hline Unskilled birth attendant & $14(12.0)$ \\
\hline \multicolumn{2}{|l|}{ Do you like the way the TBA treat you during delivery } \\
\hline Yes & $26(70.3)$ \\
\hline No & $11(29.7)$ \\
\hline \multicolumn{2}{|l|}{ If yes to the above, why? } \\
\hline I felt relaxed and comfortable & $5(19.2)$ \\
\hline Low cost & $6(23.1)$ \\
\hline Given adequate attention & $12(46.2)$ \\
\hline Polite and caring & $3(11.5)$ \\
\hline
\end{tabular}

\section{Knowledge of ANC and Factors Influencing Choice of Delivery Place}

Most of the ANC attendees (55.4\%) believe that ANC should commence the moment they know they are pregnant. One-third (33.4\%) believe that the ANC tests are not necessary.
The majority of the participants, 309 $(80.1 \%)$, say swelling of legs can be a sign of a problem in Pregnancy, 307 (80.2\%) say Hypertension can occur during Pregnancy, 270 $(70.5 \%)$ say a normal pregnancy can have complications along the line while $14.9 \%$ believes that occasional bleeding in Pregnancy may be normal. More than a third (39.4\%) 
believe they can be delivered at home if their ANC is normal. Less than a quarter $(22.3 \%)$ believe that the cost of care during childbirth at the hospital is rather too high.
The following are reasons that can make one deliver outside the Hospital; Distance (62.1\%), Husband hindrance (53.2\%), Not buying delivery items $(55.9 \%)$, and those with fewer pregnancies $[1,2](76.7 \%)$.

Table 3. Knowledge of ANC and Factors Influencing Choice of Delivery Place

\begin{tabular}{|c|c|}
\hline Variables & Frequencies n $(\%)$ \\
\hline \multicolumn{2}{|l|}{ Knowledge of when ANC should start } \\
\hline ANC attendance begins the moment I know I am pregnant & $224(55.4)$ \\
\hline ANC should begin only when the Pregnancy is noticeable & $180(44.6)$ \\
\hline \multicolumn{2}{|l|}{ The tests done during ANC are not necessary } \\
\hline Yes & $135(33.4)$ \\
\hline No & $269(66.6)$ \\
\hline \multicolumn{2}{|l|}{ Swelling of legs can be a sign of a problem } \\
\hline Yes & $323(80.0)$ \\
\hline No & $81(20.0)$ \\
\hline \multicolumn{2}{|l|}{ Hypertension can occur during Pregnancy } \\
\hline Yes & $329(81.4)$ \\
\hline No & $75(18.6)$ \\
\hline \multicolumn{2}{|l|}{ A normal pregnancy can have complication along the line } \\
\hline Yes & $290(71.8)$ \\
\hline No & $114(28.2)$ \\
\hline \multicolumn{2}{|l|}{ Occasional bleeding is normal occurrence during Pregnancy } \\
\hline Yes & $60(14.9)$ \\
\hline No & $344(85.1)$ \\
\hline \multicolumn{2}{|l|}{ I can deliver at home if my ANC is uneventful } \\
\hline Yes & $159(39.4)$ \\
\hline No & $245(60.6)$ \\
\hline \multicolumn{2}{|l|}{ Is the cost of hospital delivery high? } \\
\hline Yes & $90(22.3)$ \\
\hline No & $314(77.7)$ \\
\hline \multicolumn{2}{|c|}{ Can distance to health care centre cause a woman to deliver at home } \\
\hline Yes & $251(62.1)$ \\
\hline No & $153(37.9)$ \\
\hline \multicolumn{2}{|l|}{ Can failure to book for ANC be a reason for home delivery } \\
\hline Yes & $72(17.8)$ \\
\hline No & $332(82.2)$ \\
\hline \multicolumn{2}{|l|}{ Can husband be hindrance to hospital delivery? } \\
\hline Yes & $215(53.2)$ \\
\hline No & $189(46.8)$ \\
\hline \multicolumn{2}{|c|}{ Can lack of buying delivery items cause a woman to deliver at home } \\
\hline Yes & $226(55.9)$ \\
\hline No & $178(44.1)$ \\
\hline Do you like the lithotomy of delivery in the hospital? & \\
\hline
\end{tabular}




\begin{tabular}{|l|l|}
\hline Yes & $282(69.8)$ \\
\hline No & $122(30.2)$ \\
\hline \multicolumn{2}{|l|}{ How many pregnancies have you had in the last 5 years } \\
\hline 1 & $179(44.3)$ \\
\hline 2 & $131(32.4)$ \\
\hline 3 & $58(14.4)$ \\
\hline 4 & $36(8.9)$ \\
\hline
\end{tabular}

Mean number of pregnancies $2.76 \pm 1.51$. The mean ANC visits in current Pregnancy $2.55 \pm 0.98$

\section{Relationship Between Place of Delivery and Some Demographic Factors}

Significant factors influencing the participants decision whether to deliver in the hospital or at home by this study participant includes; the level of educational, religion, means \& ease of transportation, satisfaction with the healthcare workers / last delivery experience, the position (lithotomy) used at delivery and the number of pregnancies where the multi-gravida mostly prefers home deliveries $(\mathrm{p}=<0.0001)$ Table 4 .

Table 4. Relationship Between Place of Delivery and Some Demographic Factors

\begin{tabular}{|c|c|c|}
\hline Variables & Chi-square & p-value \\
\hline \multicolumn{3}{|l|}{ Desire to deliver at the place of your last child birth? } \\
\hline Educational status & 22.531 & $<0.0001$ \\
\hline Previous experiences with home or hospital deliveries & 42.610 & $<0.0001$ \\
\hline Satisfaction with the behaviour of health workers & 27.593 & $<0.0001$ \\
\hline Ease of transportation during labour & 16.020 & 0.031 \\
\hline The lithotomy position of delivery & 30.617 & $<0.0001$ \\
\hline Religion & 19.172 & $<0.017$ \\
\hline Number of pregnancies in the last five years & 48.373 & $<0.0001$ \\
\hline
\end{tabular}

\section{Discussion}

Most respondents in the present study were in their third decade of life $(21-30$ years $)$ with a mean age of 27.6 \pm 5.0 . This is similar to an earlier report by [7] in Kano, Nigeria. In contrast, [6] found a higher mean age from Ekiti South-Western Nigeria.

This observation may be attributed to the geopolitical zoning (Northern vs. Southern Nigeria) with its similarity in culture and religion that influences the age of marriage and childbearing. More than two-thirds of the participants in this study had their last delivery in the hospital.

Our finding is similar to the Ekiti study, with the similarity in the educational status of our respondents being a possible explanation for the similarity. A significant number (29\%) had their last deliveries at home with approximately, one-sixth (17.8\%) of them still willing to be delivered at home in their next delivery. This is at sharp variance with the findings among Eritrean women in which almost three-quarter of them delivers at home [15]. The difference may be due to the variation in study sites and the rural nature of their study compared to ours.

The reasons for the preference of home delivery by some in this study were sudden onset of labour, lack of transportation means, and high hospital cost. Others are; a distance of the health facility, husband hindrance, and not having delivery items ready. This is not surprising as most of our study participants are from a lower social status. In addition, we found participants in this study preferring to be delivered at home by the unskilled TBAs because of unfettered attention (46.2\%) 
accorded them and the lower cost $(23.1 \%)$ of delivery when compared with delivery at the hospital. About one-quarter of the women believes that the cost of delivery at the hospital is high.

Similar findings have been reported by other authors $[6,15]$. The reason for this preference may also be due to habit, which will explain this irrational choice despite knowing the risk involved [16]. Home deliveries were conducted by the TBA in about a third of cases $(31.6 \%)$ among those that chose home deliveries. This may not be a true reflection as the responders believed that others that conducted their deliveries at home were Doctors and Nurses. This assertion may be wrong as many in this environment address every male that works in the hospital as a doctor and females as Nurses.

Although, most in this study understand that leg swelling in Pregnancy may be a signal to danger. A majority also know that Hypertension can occur in Pregnancy and that a hitherto normal pregnancy may get complicated [17]. Significant factors influencing the choice of where to be delivered include; educational status, previous experiences, satisfaction with the healthcare worker's attitude, religion, lower parity, and delivery positioning (lithotomy) at the Hospital [18-21].

A third was of the opinion that the ANC sets of investigations were not necessary; the relatively low level of education may justify this unhealthy belief. Some believe that once their antenatal care attendance period is uneventful, then they can be safely delivered at home. Probably due to their religion, healthcare worker's attitude, and or dislike for the lithotomy position by some respondents.

\section{References}

[1] World Health Organization, WHO maternal mortality fact sheet 2018 .

[2] Dahal RK. 2013. Factors influencing the choice of place of delivery among women in Eastern rural Nepal. International Journal of Maternal and Child

\section{Conclusions}

Most participants had their deliveries in the hospital, but a significant number (29\%) still delivers at home despite knowing that Hypertension can occur in Pregnancy and that normal Pregnancy can become complicated. Reasons for their decision were due to lack of transportation means, the attitude of healthcare workers, and high cost of hospital deliveries. The major determinant of choice of place of delivery are; educational status, religion, previous experience, the attitude of healthcare workers, and parity.

\section{Recommendations}

1. Efforts should be made to make universal health coverage through the inclusion of every woman of childbearing age in the scheme.

2. Training and retraining of healthcare workers on attitudinal change.

3. Education should be made compulsory up to the secondary school level.

\section{Acknowledgement}

Mr Caleb Eselema Odonye is acknowledged for his assistance in data entering and analysis. All the mothers that participated in this study are also appreciated.

\section{Conflict of Interest}

There is none to be declared.

\section{Funding}

The research was funded by the Dalhatu Araf Specialist Hospital Research Unit.

Health. $\quad 1 \quad$ (2): $\quad 20 \quad-\quad 37$. www.semanticscholar.org/paper/factors-influencingthe-choice-of-place-of-delivery-dahal.

[3] Adegoke A.A, Hofman J.J, Kongnyuy E.J, van den Broek N. 2011. Monitoring and evaluation of skilled Birth Attendance: A proposed new 
framework. Midwifery. 27 (1): 350 - 359 . www.academia.edu/24971185/Adegoke.

[4] Thomson A. The joint WHO/ICM/FIGO statement on skilled attendants at birth. Midwifery 2005; 21(1): 1 - 3 .

[5] Adegoke A.A, Mani S, Abubakar A, van den Broek N. 2013. Capacity building of skilled Birth Attendants: A review of pre-service education curricula. Midwifery. 29 (7): e64 - e72. www.pubmed.ncbi.nlm.nih.gov/23199532/.

[6] Oluwadare T, Adegbilero - Iwari O, Fasoro A.A, Oluwafemi F.S. 2021. Determinants of choice of place of delivery among women of childbearing age in Ido - Ekiti Nigeria. Annals of Romanian Society for Cell Biology. 25 (4): 4554 - 4565. www.researchgate.net/publication352017679.

[7] Abubakar S, Adamu D, Hamza R, Galadima J.B. 2017. Determinants of home delivery among women attending ante-natal care in Bagwai town Kano Nigeria. African Journal of Reproductive Health. 21 (4): 73 - 79. www.ajrh.info/index.php/ajrh/article.

[8] World Health Organization, WHO report on high-rate mortality fact sheet 2017.

[9] Ajayi A.I, Akpan W. 2020. Maternal health care services utilization in the context of 'Abiye' (safe motherhood) programme in Ondo State Nigeria. BMC Public Health. 20 (1): 362 - 370. www.pubmed.ncbi.nlm.nih.gov.

[10] Idris S.H, Gwarzo U.M.D, Shehu A.U. 2006. Determinants of place of delivery among women in a semi-urban settlement in Zaria, Northern Nigeria, Annals of African Medicine. 5 (2): 68 - 72 . www.bioline.org.br/pdf.

[11] Abe E, Omo-Aghoja L.O. 2008. Maternal mortality at the Central Hospital, Benin City, Nigeria: A ten-year review. African Journal of Reproductive Health. 12 (3): 17-26. www.scirp.org. [12] Ewa EE, Lasisi CJ, Maduka SO, Ita AE, Ibor UW and Anjorin OA. 2012. Perceived factors influencing the choice of antenatal care and delivery centers among childbearing women in Ibadan North South-Western, Nigeria. Ethiopian Journal of Environmental Studies and Management. 5 (4): 373 - 383. www.semanticscholar.org/paper.
[13] Reproductive Health resource survey at primary health care level of government facilities FMOH, Abuja; 2002.

[14]Envuladu E.A, Agbo H.A, Lassa S, Kigbu J.H, Zoakah A.I. 2013. Factors determining the choice of a place of delivery among pregnant women in Russia village of Jos North, Nigeria: achieving the MDG s 4 and 5. International Journal of Medicine and Biomedical Research. 2 (1): 23 - 27. www.researchgate.net/publication/269604857-.

[15] Kifle M.M, Kesete H.F, Gaim H.T, Angosom G.S, Araya M.B. 2018. A health facility or home delivery? Factors influencing the choice of delivery place among mothers living in rural communities of Eritrea. Journal of Health, Population, and Nutrition. $37 \quad$ (1): $\quad 22 \quad$ - 36. www.researchgate.net/publication/328431657-.

[16] Broda A, Kruger J, Schinke S, Weber A. 2018. Determinants of choice of delivery place: Testing rational choice theory and habitus theory. $\begin{array}{lllll}\text { Midwifery. } & 63(4): & 33 & - & 38 .\end{array}$ www.daneshyari.com/article/preview.

[17] Kumari B.S, Thompson S. 2016. Choice of Place of Delivery - Home or Hospitals, among mothers of Urban slums of Nalgonda district. Indian Journal of Applied Research. 6 (1): 336 - 338. www.worldwidejournals.com/indian-journal-ofapplied-research(IJAR)/fileview.

[18] Uwiduhaye M, Mung'atu J.K. 2016. Modelling factors influencing the choice of Delivery place at birth among pregnant women in Rwanda using Multinomial logistic method. International Journal of Science and Research. 7 (11): 124 - 129. www.ijsr.net/archive.

[19] Okang C.A, Kaseje D. 2015. The Pull and Push factors influencing of place and delivery attendant in Urban slums of Nyalenda, Kisumu East District, Kenya. International Journal of Humanities and Social Science. 5 (1): 133 - 140. www.ijhssnet.com/journals.

[20] Gebregziabher N.K, Zeray A.Y, Abtew Y.T, Kinfe T.D, Abrha D.T. 2019. Factors determining the choice of place of delivery: an analytical crosssectional study of mothers in Akordet town Eritrea. BMC Public Health. 19 (1): 924 - 934. www.bmcpublichealth.biomedcentral.com/track. 
[21] Nwankwo O.N.O, Ani O.E, Akpoke M, Ugwa E.A. 2019. Determinants of choice of place of delivery among women attending two referrals
Hospitals in Kano North-West Nigeria. Nigeria Medical Journal. 60 (2): 68 - 75 . www.nigeriamedj.com/article. 